\title{
Chapter 7 \\ Organized Mobility and Relational Turnover as Context for Social Mechanisms: A Dynamic Invariant at the Heart of Stability from Movement
}

\author{
Emmanuel Lazega
}

Movements following paths that Harrison White (1970) calls "vacancy chains" (p. 17) can be seen as forms of rotation across systems of places that are often socially organized circuits. ${ }^{1}$ White calls such movements "mobility in loops" (p. 380). From his structural perspective, not all loops or systems of places are necessarily visible to the actors involved, or even to managers of organizations who track, measure, and sometimes steer other people's careers. Internal or external labor markets were the first contexts White (1970) identified for such circuits. These loops are also the daily focus of attention of lay citizens and professional observers alike, representing revolving doors for a wide range of actors. That group includes high-status people between the business world and government-from investment banks to the Treasury, for example. It is composed partly of workers subjected to employment "flexibility" and struggling step by step to make the necessary moves a reality while keeping limbos between jobs as short as possible. It also encompasses managers rotating their employees and themselves from one service to the other in the company, as with associates assigned to different partners and clients of the firm in successive and heterogeneous task forces. It consists, too, of directors moving from one corporate board to the other in a closed chain, and of sales representatives participating each year in dozens of recurrent and similar trade fairs of their industry (Brailly, Favre, Chatellet, \& Lazega, 2015). Many analogous circuits

\footnotetext{
${ }^{1}$ The term place is used here in a general sense to refer to a location that can be occupied by an individual in any formally organized circuit, which can be geographical, organizational, or both. It is to be distinguished from the term position (White, Boorman, \& Breiger, 1976) - a set of structurally equivalent actors called a "social niche" (Lazega, 2001, p. 25) when the ties between actors in the position are dense. A position makes sense in a system of positions (or niches) that differs from, though always combined and coevolving with, the system of places (Lazega, 2013). Space (contiguity) and network (connectivity), for example, are both different and related.

E. Lazega $(\square)$

Department of Sociology at the Institut d'Etudes Politiques de Paris,

Centre for the Sociology of Organizations, 19 rue Amélie, 75007 Paris, France

e-mail: emmanuel.lazega@sciencespo.fr
}

J. Glückler et al. (eds.), Knowledge and Networks, Knowledge and Space 11,

DOI 10.1007/978-3-319-45023-0_7 
exist around and beyond labor markets as well. Migrants in comparatively wealthy countries attract people from the same place of origin and sometimes return there after having been overused to sweep floors and dig holes. Students can spend semesters pursuing their curriculum in universities of different countries before returning to their alma mater. Geographers and sociologists can ultimately examine broad residential forms of mobility of individuals and entire communities. By doing so, they see, for example, mobility in loops of neighborhoods or as life-cycle-related mobility of young adults moving together into new places, then to bigger places when they have children, then to smaller ones when the children leave home.

Sociologists have also looked independently at turnover in networks of personal relations. In an increasingly rich body of literature, they have described and modeled relational turnover, using statistical tools designed to deepen the understanding of network dynamics (Snijders, 1996; 2005). Relational turnover is defined in this chapter as the set of changes observed in an actor's relationships between two moments in time (e.g., the creation or addition of new relationships, the destruction or disappearance of previous relationships, and the maintenance of relationships). Dynamic models of coevolution of behavior and networks are based on analyses of this relational turnover in members' profiles and in the composition and structure of the collective. When people close their eyes and ignore a situation marked by conflicts of interest, is it because they have become friends with someone who tends to do the same thing and influences them in that direction? Or is it because from the outset they chose friends from among people who, like themselves, close their eyes when confronted by situations of this kind? Often, both answers are true, but each effect has a relative weight that can be measured only by observing and analyzing behavioral changes and relational turnover over time. Without such analyses of coevolution of behavior and relational turnover, intuitions about concerted ignorance as a complex phenomenon, i.e. difficult to observe, remain poor and explanations of this phenomenon as a social process remain untested. ${ }^{2}$ The act of changing structural forms and relational infrastructures triggers changes in social processes downstream. All the main social phenomena, such as solidarity, exclusion and discrimination, social control, conflict resolution, learning, socialization, regulation, and institutionalization, have a relational dimension, are a function of relational infrastructures, and reshape structure, at least opportunity structures. ${ }^{3}$

\footnotetext{
${ }^{2}$ In many ways work by Snijders $(1996,2005)$ strongly reflects the best social science epistemological practice in which researchers measure, formalize, and model the coevolution of behaviour and interdependencies, of interdependencies and conflicts between actors, both individual and collective. This approach compares models against reality and measurements of reality, but also inspires new intuitions about realities too complex and difficult to observe directly. In short, models, measurements, theories, and the object of analysis coevolve.

${ }^{3}$ The list of social processes that facilitate collective action between status competitors and that can be modeled by network analysis is indefinite (i.e., there is no finite list of these processes) because no social processes exist without a relational dimension. Relational processes that characterize collective action undertaken by interdependent entrepreneurs have been the object of neostructural formalizations: integration, assimilation, cooptation, balance of power, evaluation of product quality, exploitation, extraction of economic performance, discrimination, and desolidarization. These
} 
Often overlooked in the literature, however, is the systematic, recursive, and transformative link between the two realities - mobility (rotation) across systems of places and relational turnover - and that link's implications for social life. There is a connection between movement and human relationships, for actors switch places in these circuits and change occurs as a consequence, at least in part, in their respective sets of relationships - and, by extension, in their relational capital. In addition, the latter change affects the evolution of the system of places itself, an evolution that is apparent only if places are regarded not as purely contextual and exogenous but rather as endogenized by members themselves and thus as endogenous to the mechanisms under study. The connection between movement and relational capital is often explored in detail in specific areas of social life. Migration networks, for example, are prototypical. When members of a family migrate across continents, separations between them and the family remaining in the country of origin are often devastating for individuals and social communities. The focus in studies on their situation is therefore justifiably on coping with the costs of leaving families behind, on marginality, loneliness, and the creation and management of new relationships by agents striving for their own or their children's social mobility and assimilation. But the mechanics and social costs of this link also deserve exploration, as do the effects that such movements have on the structure and governance of the system of places. It is about the stability and change of the system and the opportunity structure that it represents for its members.

The structuration, or transformation, of organized mobility and relational turnover (OMRT) may be called the complex dynamics that lead individuals and organizations to change part of their relational and social capital as they switch places in relatively closed, partly overlapping loops, whether formally institutionalized or emergent. These dynamics trigger social processes that may, under specific circumstances, reshape the initial opportunity structure of some members of the setting but not that of others. Each domain of social and economic life and every field of attendant research in the social sciences has its OMRT structuration processes. I define OMRT structuration as the dynamic link - as mediated by "dynamic invariants"between places and positions. I use the label organized to qualify mobility, for both social actors and the social system create paths and rules for movements that are not allowed to be random. Whether physical or social or both, these linked, articulated movements and changes are fundamental to social structure and social order in the

processes, which together contribute, for example, to cooperation between competitors, remain separate only for analytical purposes. They are dynamically linked, as by retroactive effects. The redefinition of rules can engender new solidarities. Normative beliefs produced by the regulatory process influence choices of advisors and, hence, learning, among other processes. Controversies in part energize the evolution of structures that facilitate collective learning. They contribute to the endogenous formation of the constraints that actors can then consider legitimate or not legitimate and that they submit to more or less voluntarily. Research is only just beginning on the manner of connection (articulation) between these processes and the forms of social discipline that they create (see Lazega, 2009; 2012). 
organizational society (Perrow, 1991). ${ }^{4}$ They are created by the social organization of these milieus and end up, under conditions that remain to be spelled out, restructuring these milieus, taking some members somewhere and others nowhere. Dynamics of OMRT are not simply a recursive and alternating movement between two separate poles influencing each other while competing in doing the same thing. OMRT dynamics involve more complex evolution because they have an impact on fundamental social processes. These processes all have a relational dimension, and all depend on relational infrastructure that facilitates their deployment (Lazega, 2001, 2003, 2012).

A neostructural approach to the relationship between behavior and position in the social structure takes these dynamics into account and provides this endogenous understanding of social change and system stability. ${ }^{5}$ From this perspective, position in the structure is not a static place in a static order. It results from specific social dynamics. These dynamics can be approached through the notion and measurements of relational infrastructures, i.e.social forms in the sense meant by Simmel (1908/2009). At least two such forms are needed to position actors in the structure, describe their attempts to modify their opportunity structure, and explain the deployment of generic social processes that help them, as members of a collective, deal with the pitfalls of collective action (e.g., freeloading and crowding in the production and consumption of collective goods). The two social forms are niches and status, which represent underlying social differentiations, horizontal and vertical, in the social space. It is not surprising that status as a social form is key to the deployment of social processes. In general, sociological theory, status refers to a member's relative position in the formal hierarchy of the group, as well as in its internal networks of exchanges (Blau, 1964; Hughes, 1945; Lenski, 1954; Merton, 1957). Members' status can be understood as a translation of their present and past contributions to the group's cooperative system into a right to participate actively, and sometimes to lead. Sociological classics have long stressed the salience of many dimensions of social status and social approval. Weber (1924), for example, distinguished between three-economic (based on the control of production apparatus), social (based on honor and prestige derived from birth and from human capital, or education), and political (based on control of the state apparatus) - which can overlap in stable economic conditions.

\footnotetext{
${ }^{4}$ The term organizational society has several dimensions. According to Perrow (1991), it means that large-scale public or private organizations "absorb" (p. 726) societal functions that can be performed by communities. It also means that a system of interdependent organizations interlinked at the mesolevel in a multilevel network shapes the opportunity and constraint structure of citizens by coordinating, for example, various forms of opportunity-hoarding (Tilly, 1998). Lastly, the term organizational society is a metaphor for the tendency of individuals to act at the individual and organizational levels simultaneously and for the observation that domination (in the sense meant by Weber, 1924) is linked to the control of organizations as "tools with a life of their own" (Selznick, 1949, p. 24).

${ }^{5}$ Contemporary neostructuralism is different from the structuralism of the 1960s in that the former draws on a theory of individual and collective action to articulate structure, culture, and agency (Archer, 1988; Lazega \& Favereau, 2002).
} 
This chapter focuses on status to theorize the relationship between OMRT dynamics and social processes, in particular collective learning. In neostructural vocabulary social processes differ from OMRT dynamics. In a collective of interdependent members, social processes are combined and iterated actions and interactions that help these members manage the dilemmas of collective action by constituting a form of social discipline that the same members consider to be legitimate, at least temporarily. OMRT dynamics are the micro- and macrophenomena that shape and reshape these social processes and can be considered as being among the determinants thereof. The process taken as an example in this chapter is collective learning. In this process status is a central relational infrastructure (Blau, 1964; Krackhardt, 1990; Lazega, 1992). Indeed, the quest for status (an individual's importance) in the collective, which presupposes participation in status competition, is another way of seeking to modify one's opportunity structure to one's advantage. Social status is an inevitable basis for strategies intended to modify opportunity structures. In effect, the multiple dimensions of social status can be measured as concentrations of different kinds of resources. Network analysis offers measures (essentially, centrality and prominence), that identify heterogeneous and endogenous forms of status (and not simply exogenous forms as in Weber). From a more endogenous perspective, a person can achieve status in many local ways, such as by demonstrating great competence, assuming administrative responsibilities, gaining popularity, concentrating various sorts of specific assets, or even receiving the endorsement of members with status. Status competition paves the way to a mandate to represent the collective, control resources, gain authority, and define the terms of social exchanges, but also to protect one's regulatory interests and partially resist being thrust from "above" into overt competition.

Status will thus help construe and measure these dynamics for an indispensable process of collective action and social life in communities in which it is a notable relational infrastructure: collective learning. This example will illustrate that such infrastructures have a salient role in linking OMRT and social processes. Theorizing these dynamics shows that geographers, historians, and sociologists have a strong interest in collaborating in research on OMRT structuration and on the social costs it entails.

\section{Illustration: A Spinning-Top Model of Collective Learning}

It may be useful to start this exploration with an empirical case study that illustrates some of the complexities of OMRT dynamics. The research was used to explore the OMRT model and permits a look at intraorganizational learning networks at the intersection of the sociology of organizations, economic sociology, and the sociology of law. Intraorganizational learning has been considered a significant process in organizations ever since the publication of March and Simon's (1958) perspective. The relevance of studying this process has grown with the number of knowledgeintensive organizations, which thrive on innovation, and with the concomitant 
search for new competitive advantages. Learning as a relational and interactive process can be captured through the study of advice networks. In organized contexts it is usually possible to consult with someone through social exchange in which members obtain advice in exchange for recognition of the advisor's status and authority (Blau, 1955), which can be called epistemic status. Members with epistemic status usually have hierarchical authority, professional authority, or expert authority, if not two or even all three of these forms of authority combined (Lazega, 1992). ${ }^{6}$

The case is based on an organizational and longitudinal network study of adviceseeking among judges at the Commercial Court of Paris. The French Commercial Court is a judicial, local, first-level consular jurisdiction dealing with commercial litigation and bankruptcies in the French economy. ${ }^{7}$ Its judges are unpaid lay volunteers from the local business community, and they are expected to pool their experience and knowledge of business practices and customs in order to find solutions to conflicts therein. They are elected or coopted for 2- or 4-year terms (but no more than 14 years) by an electoral body composed of other judges already sitting at the same court and by representatives of the trade associations of the Chamber of Commerce of their local jurisdiction. Most consular judges remain for the whole 14-year tenure, allowing social groups to form and be sustained within the organization. Of the 156 consular judges at the Commercial Court of Paris in 2005, $38 \%$ were bankers and insurers, for the financial industry is currently the only one that can afford to send large numbers of senior managers to perform as judges in such an institution (see Lazega, Lemercier, \& Mounier, 2006; Lazega \& Mounier, 2009, 2012; Lazega, Mounier, Snijders, \& Tubaro, 2012; Lazega, Sapulete, \& Mounier, 2011).

The court is composed of 20 specialized and general chambers dealing with bankruptcies and widely diverse forms of commercial litigation (such as corporate law, European Union law, international law, unfair competition, multimedia, and new technologies). It handles around $12 \%$ of all the commercial litigation in France, including large and complex cases for which companies decide not to go to arbitration courts. The consular judges rotate annually from one chamber to another. The policy of rotating judges across the chambers is intended to prevent corruption and

\footnotetext{
${ }^{6}$ Expert authority can be defined as professional authority exercised among nonprofessionals, i.e. by sharing minimal knowledge for action with the latter across the professional/lay boundary.

${ }^{7}$ An explanation of the term consular is in order. The consulat was a mode of urban government practiced in the Middle Ages in the southern part of the Kingdom of France by cities with a right to self-administration and self-defense. Consulatus is a noun formed from consul, meaning "council." The word referred to a community's ability to deliberate in an assembly (likewise called the consulat.). Urban communities governed by a consulat could call themselves cities. All had markets, and many had fairs. In a régime consulaire the community governed itself through consuls, who varied in number and qualification. Merchants organized as socially distinct guilds occupied a pivotal place in the régime consulaire. Drawing on the lex mercatoria (commercial law), they managed to negotiate, with the emerging French state, something akin to joint regulation of their business activities within the consulat framework: Their local self-regulation was to be founded on the state's sanctioning power. The state, whose own administration was still embryonic, may paradoxically have seen this cooptation by local merchants as a means of further extending its central control over the country. A major component of the consular regime is the tribunal de commerce, or commercial court, whose purview evolved over time.
} 
conflicts of interests (as could occur if judges were to come from the banking industry and concentrate in bankruptcy chambers).

Tasks are complex, and judges have discretion in many areas of business law. Disagreements over solutions to many legal problems abound. Commercial litigation varies, with conflict resolution often depending on knowledge of the specific business and industry in which the conflict has arisen. To manage these uncertainties intraorganizationally, the judges are keen on seeking each other's advice, drawing on their professionally heterogeneous set of colleagues. When a judge coming from the hotel industry must decide in a case brought by two opposing banks, for example, she has many banking-sector colleagues with whom she can consult about customs and current issues in the financial industry or about banking law.

Data for this chapter was gathered at three points in time (fall 2000, fall 2002, and fall 2005). All the judges were interviewed face to face about their adviceseeking among each other. The following name generator was used:

Here is the list of all your colleagues at this Tribunal, including the President and VicePresidents of the Tribunal, the Presidents of the Chambers, the judges, and "wise men." Using this list, please check the names of colleagues from whom you have asked advice about a complex case in the previous two years or with whom you have had basic discussions outside formal deliberations in order to elicit a different point of view on it.

A high average response rate $(87.1 \%)$ over the three stated periods made it possible to reconstitute the entire advice network (outside formal deliberations) among judges at this courthouse at each point in time. The number of judges at the court from 2000 to 2005 varied from 151 to 156 .

Longitudinal analyses of the advice network among these lay judges have facilitated a close look at the structural factors that explain relational turnover in the network - that is, the creation of new ties and the discontinuation of previous ones. This work was based on Snijders's $(1996,2005)$ Siena models of dynamic analysis of the evolution of this network (see Lazega et al., 2006; Lazega et al., 2012). They tease out a cyclical process of centralization and decentralization in the network over time. Movement in this organizational system of places, change in the system of places, and the attendant emergence of status are all visible in this cycle of centralization-decentralization. Through these cyclical dynamics individuals eventually attain epistemic status and displace incumbent status-holders at the top of the hierarchy. Such evolution helps reproduce the persistent organizational structure and characterizes the continuous collective learning process in the organization.

\section{OMRT Transformations as Determinants of Collective Learning: Cyclical Dynamics of Advice Networks}

An advice network represents a set of paths through which appropriate information circulates among members of an organized setting. The allocation of this resource through informal ties and interactions reduces the costs of its acquisition during the 
process of making decisions to solve problems. Members of organizations see expertise and experience as accumulated by the organization, and they rely constantly on advice from others. However, intraorganizational learning through advice-seeking does not simply result from the accumulation of individually and informally acquired information. The process is socially organized in a sophisticated way.

In organizations examined by researchers, advice-seeking converges toward senior and recognized members and reflects a process of epistemic alignment with (or orientation to) members who have gained epistemic status and the "authority to know," who give social approval for specific decisions, and who contribute to integrating the organization by linking the individual, group, and organizational levels. This alignment may be thought of as a key ingredient of intraorganizational learning. Providing a social incentive for actors to share their knowledge and experience with others, a status hierarchy helps explain the social organization of the learning process. For example, social exchange and status help solve a learning dilemma in which it is rational for individuals to pursue the maximum organizational share of joint learning by taking more knowledge than they give. At the same time, the relative withholding of knowledge reduces the total amount of joint learning from which persons attempt to appropriate their individual share (Larsson, Bengtsson, Henriksson, \& Sparks, 1998).

Because advice networks are usually shaped by such status 'games', they are usually highly centralized. They exhibit a pecking order that often closely follows the hierarchical structure of the organization (Lazega, 2014). Members of formal organizations rarely declare that they seek advice from "people below" in this pecking order. In addition to a core set of central advisors, the periphery of the network can be complex and characterized by homophilous (Lazega \& van Duijn, 1997) horizontal ties (i.e., ties among peers). Members use such ties to mitigate the negative effects that this strict rule can have on intraorganizational action and learning (e.g., unwillingness to show that one does not know the answer to a question). Advice networks thus tend to be both hierarchical and cohesive (at least within subsets of peers), with the hierarchical dimension usually being stronger than the cohesive one. In some firms advice ties are crucial in facilitating the flows of other kinds of resources in coworkers' and friendship ties (Lazega \& Pattison, 1999).

A "spinning-top model" accounts for the dynamics of advice networks in organizations by furnishing a main metaphor for research on the relationship between formal organization and intraorganizational process. It shows that intraorganizational collective learning depends on the organization's capacity to generate an elite group of authoritative advisors with epistemic status that remains stable. By contrast, advice ties among other organizational members undergo rapid turnover (due, say, to rotation policy, career movement, or the need for new knowledge that old advisors cannot offer; Ortega, 2001; Kane, Argote, \& Levine, 2005). More generally, the spinning-top model illustrates a new approach to the relationship between formal organization and informal social behavior and processes.

As a model for a dynamic process, the spinning-top heuristic brings together at least three components: a rotating body, a rotation axis, and a fragile equilibrium 
that depends partly on characteristics of the first two components. I define these terms metaphorically and loosely. The rotating body represents the learning organization - the population of judges who switch places once a year in a circular system of places, as with a carrousel or "mobility in loops" (White, 1970, p. 380). The rotation axis represents a pecking order: a vertical differentiation between the judges and the emergent hierarchy of members with epistemic status. This axis can be pictured as the spinning top's shaft, which supplies the angular momentum that keeps the spinning top erect. It allows learning to take place in a system that remains stable thanks to its movement. The fragile equilibrium created by the rotation movement represents the structural condition for learning collectively in the organization and depends on the stability of the rotation axis and the shape of the organization. Time is taken into account through rotation and speed. These members have the authority to know in the organization. Formal structure is summarized in rotation rules across intraorganizational boundaries and in status differences. Infrastructural stability, that is necessary for collective learning and social processes in general, comes from movement.

The endogenous evolution of advice networks is characterized by three interrelated moments. First, the centrality of members with high epistemic status varies over time. It initially tends to be reinforced. Pivotal members become ever more central in a Matthew effect (Merton, 1968): The more they attract advice-seekers, the more their reputation grows and, in turn, the more they are sought out. Among other members, there spreads the impression that turning to such a source for advice is safe and legitimating for their own knowledge claims, and that making this choice signals a rise in relative status. Concentration of epistemic authority thereby intensifies with the centralization of advice networks as learning comes to depend on a dwindling number of sources of authoritative knowledge.

Second, in real-life organizations this centralization creates an overload for members with high epistemic status. These members tend to manage this overload by sharing some of their epistemic status, redirecting advice-seekers to other sources through recommendations. When advice from the handful of the supercentral advisors becomes inaccessible, irrelevant, inaccurate, untimely, or rare, members turn to these other advisers, creating new epistemic stars. Sharing epistemic status (a form of delegation) enlarges the number of advisers and lessens the centralization of the network.

Third, the expansion in the number of central members with high epistemic status in the organization creates a problem of epistemic conflicts, consensus, and coordination among epistemic authorities. If it is easy to co-orientate with them, equilibrium is established. If not, conflicts between epistemic authorities trigger recentralization. When collective action eventually becomes endangered by an excessive number of epistemic leaders, some of them withdraw or retire, and others are disqualified in one way or another. As their numbers decrease, it becomes easier at the top to recreate consensus around a common definition of the situation, to give coherent social benchmarks for homogeneous judgments of appropriateness (Lazega, 1992). 
These dynamics of centralization and decentralization in advice networks may not be purely endogenous. In other words, it might not be that overload due to centralization leads the supercentral advisors to redirect advice-seekers to surrogates and thereby create new epistemic stars. The pattern of advice relations can be influenced by the content of the advice sought, and external events may make one potential advisor a better source of advice than another. Nonetheless, the existence of this endogenous dimension of the process provides at least one mechanism that explains how particular supercentral elites are able to stabilize their position and surf at the top of the structure thanks to strong competition for epistemic authority and status.

This picture is heuristic for several reasons. First, it suggests that time is important in allowing organizations to select members who possess epistemic status. The epistemic status of a person appreciates with his or her reputation for expertise, with the capacity to provide quality control without raising excessive controversy or conflict over the definition of the situation, and with the trained capacity to speak legitimately on behalf of the collective. Acquiring this status takes effort and time. The authority to know stems from prolonged individual and collective investment that can be ruined if members with epistemic status leave or behave too opportunistically. The equilibrium achieved by the spinning top thus suggests that members with status and epistemic authority in the organization have a strong incentive to keep both over time, even at extra expense, to avoid losing advantages that come with their relative standing (see Frank, 1985).

Second, this heuristic suggests that the equilibrium achieved by the spinning top is fragile. It is not only the centrality but also the number of members with high epistemic status that varies over time. There are several conceivable reasons for this number's fluctuation. One is that members tend to choose advisors whom they perceive to be the most popular (i.e., already chosen by a large number of colleagues). Because such widely sought-out members within the organization are perceived to be safe and legitimate choices as advisors, their reputation grows. Given the micropolitical perspective that all people seek status and that they believe they will improve theirs, access to advisors higher up the ladder becomes in itself a sign of relative status. The implication is that a member highly sought out in time $t_{1}$ will be even more intensely sought out in time $t_{2}$.

Another reason for the rise and fall in the number of members with high epistemic status is that the first period in this process demands too much of the small circle of highly central advisors. Because these individuals often manage the overload by delegating, by referring the advice-seeker to other advisors, the number of new central advisors inflates to the point that the stability of the pecking order is jeopardized. Even without such delegation, however, the equilibrium remains fragile, and for the same reasons. These elites must thus work together to avoid destructive status competition between them and avert infighting over the definition of the situation. In turn, this strategy either triggers formal attempts at coordination among the elites or reduces the number of central advisors through retirement or delegitimation.

The existence of this oscillation in the centralization of the advice network was detected through dynamic analyses of the network's evolution (see Table 7.1). This 
Table 7.1 Collective learning as a cyclical process: increase, then decrease, of centralization in an advice network over time

\begin{tabular}{lcc}
\hline Independent variables & $\begin{array}{c}\text { Parameters for period } 1^{\mathrm{a}} \\
\text { (Wave 1-Wave 2) }\end{array}$ & $\begin{array}{c}\text { Parameters for period } 2^{\mathrm{b}} \\
\text { (Wave 2-Wave 3) }\end{array}$ \\
\hline Rate parameter & $22.25(2.03)$ & $30.58(3.14)$ \\
Density & $-1.74(0.09)$ & $-2.23(0.18)$ \\
Reciprocity & $0.95(0.16)$ & $0.71(0.13)$ \\
Transitivity & $0.50(0.04)$ & $0.19(0.01)$ \\
Popularity of alter & $3.34(0.40)$ & $3.84(0.25)$ \\
Activity of alter & $-14.44(1.84)$ & $-1.86(1.87)$ \\
3-cycles-of-generalized- & $-0.29(0.09)$ & $-0.07(0.01)$ \\
$\quad$ exchange effect & & \\
\hline
\end{tabular}

Note: Adapted from Lazega et al. (2006), p.119

${ }^{\mathrm{a}} N=91 .{ }^{\mathrm{b}} N=113$. Standard errors are in parentheses

approach entailed a close look at the structural factors that explain the network's relational turnover, that is, the creation of new ties that are added to or supplant hitherto existing ones.

This heuristic spinning-top model helps illustrate an OMRT context for processes such as intraorganizational learning. The dynamics of the advice network examined in this commercial court can indeed be represented intuitively as a spinning top. They are driven by the rotation rule in the formal structure of organization. Because judges seek advice first within their own Chamber, and because they change Chamber every year, the relational turnover in this network is high. Each year, each judge leaves behind several advisors and creates new advice ties within his or her new Chamber. This turnover, however, is compensated for by the creation of a set of advisors with epistemic status to whom judges turn for advice thanks to the Chamber in which they work. The centrality scores of members with epistemic status rise, then tend to decline over time, showing that the stabilization of this elite set of judges adds to the complexity of the dynamics of advice networks. Those dynamics come to include formally induced homophily, relational turnover, emergence of status as an endogenous effect reinforcing exogenously defined status, centralization of the advice network, and strategies of stabilization of this elite under capacity constraints. It is likely that empirical observation will find a perpetual cyclical pattern of centralization and decentralization in the advice network and that relative structural stability is achieved in part through OMRT.

These detailed analyses show that most judges achieve centrality over time, some of them to the point of losing part of it and their corresponding status in the cyclical dynamics precisely because they succeeded at sharing their status by delegating a degree of their advisory function to other colleagues (Lazega et al., 2011). Lack of space in this volume precludes detailed treatment of the substantive reasons for these dynamics of the advice networks in this specific context. The complex story behind this process of collective learning is a matter of alignment with the supercentral judges who maintain themselves by trying to exercise epistemic control and balance excessive requests for advice (when too few colleagues occupy the top of 
the pecking order) and to build consensus among the epistemic leaders (when too many of them occupy the top of the pecking order).

Further analyses (Lazega \& Mounier, 2009) have shown that this relationship between networks, rotation across places, and learning leads to collective learning when judges make decisions requiring their discretion. Such circumstances include the choice of whether or not to award damages (punitive or otherwise), to intervene in boards (by supporting minority shareholders against the management of a company), or to intervene in markets (by preventing a given party from terminating a contract that was meant to support a weaker party). What is learned in the process of collective learning, through a status game leading to upward and outward spirals of temporary epistemic status, is the solution that the court considers to be appropriate for problems for which the law does not always provide clear answers. For example, in controversies pitting bankers against colleagues mainly from the building industry, collective learning leads most judges to align their deliberations and decisions with the solutions proposed by bankers who hold a law degree. Collective learning thereby becomes equated with a form of normative alignment (if not institutional capture; see Lazega, 2011; Lazega \& Mounier, 2012) by which most judges are receptive to the solutions outlined by the dominant players in this institution (Lazega et al., 2012).

\section{Dynamic Invariant: Stability from Movement and Emergence of Epistemic Status in OMRT Structuration}

These processes are not simple. The spinning-top heuristic suggests that centralization of advice networks can remain stable or eventually expand or contract to find a balance between elite overload and conflicts between interpretations that these heterogeneous elites offer. This metaphor leads to the following claim about the structure and dynamics of advice networks and intraorganizational learning. Intraorganizational learning, as an informal process, depends on at least three factors: (a) the way that members manage their advice ties in the context of this formal organization; (b) the ways that central advisors handle overload and conflicts between definitions of the situation; and (c) the ways that formal structure can help actors deal with the advice network's oscillation between centralization and decentralization. In effect, variations in centralization over time suggest that this oscillation serves as a pump in the spinning top. If OMRT can be represented by a spinning top, it is because this image accounts for one of the main processes taking place in OMRT: the emergence of status in organized social settings.

The extent to which the emergent relational infrastructure in an organization remains the same over time-despite the combined turnover of its members and turnover in their respective relational profile - is one of the most interesting questions raised by structural analyses applied in organized social settings. In this case the emergent structure of this organization remains the same overall. The finding is 
that the emergent relational structure remains unchanged. This answer is a function of the degree to which observers focus on structure and on the dimensions of the structure they examine. As shown in the following section, the existence of a pecking order and of the core-periphery structure itself remains relatively stable thanks to their intertwining with formal hierarchy and status competition. But social differentiation measured in terms of role relationships and the division of labor shows that the relational structure does not remain the same, depending on when and where observers look at the process. Intraorganizational relational processes, such as collective learning, impose varying constraints on different kinds of members over time, and the overall relational structure reflects their changing responses to those limitations. Because the processes vary, so does the relational structure, as does the resulting emergent overall structure. Even when these dynamics are the same, they do not produce identical outcomes. They transform very different initial situations. Radical, orthodox structuralism turns out to be wrong.

\section{OMRT and Catch-up Dynamics at Superimposed Levels of Agency}

Where does the energy for rotation in OMRT come from to begin with? Posing this question is like asking what OMRTs take place in which context. Granted, OMRTs are the context of social processes, but they are themselves embedded in a wider, macrosocial context. In the example of the spinning top, the energy comes from an organizational rule that obliges representatives of an institution to switch places, a compelled rotation that is meant to control their behavior given the exogenous suspicion of corruption. But at the interorganizational level such rules do not always exist in such a formalized way. Nevertheless, if organizations are open systems, then they are part of interorganizational systems of interdependencies (observed as "networks") and are thus part of somewhat self-contained systems with a certain level of closure and their own dynamics. Movement makes sense from both below (the perspective of individual actors who orient their actions to multiple levels) and above (the fact that mesosocial order and agency take place in superimposed systems of interdependencies and collective agency) (Lazega, Jourda, \& Mounier, 2013; Lazega, Jourda, Mounier, \& Stofer, 2008). ${ }^{8}$ In such multilevel systems the temporalities of each level differ from each other. Each level must adjust and adapt to the evolution of the other level. Attempts at synchronization, however, are usually more costly for one level than for another. The level that is dominated will be compelled to pay for synchronization. This imposition can take the form of catching up in the competition for status.

The answer to the question about the origin of the energy for OMRT rotation therefore has to do with the functioning of the mesolevel in its macrocontext. The

\footnotetext{
${ }^{8}$ This logic is related to a theory of action that stresses attempts by actors to reshape their opportunity structure (see Lazega \& Mounier, 2002; Tilly, 1998).
} 
energy stems from the way power and class struggles function in the organizational society: in collective efforts to hoard opportunities and to saddle others with constraints while still encouraging or obliging everyone to compete for these same opportunities and resources. The clearest way to comprehend the origins of the energy for rotation in OMRT is to understand that it is used to concentrate power in a stratified organizational society, a society made of superimposed levels of agency. Such a society spends a great deal of energy catching up in status-related competition imposed from above, self-imposed from below, or both. That struggle is not so much about catching up with the Joneses next door as it is about adjusting to topdown constraints on maintaining or enhancing one's status. The promise of sharing power and status takes the power differentials generated by the structure of organizational society and turns them into a source of energy. Of course, decentralization is followed by recentralization. But each step in this catch-up cycle is what produces the energy for OMRT.

These OMRT are intrinsically multilevel, and the only way to understand them is to develop models depicting the dynamics of multilevel networks. These developments will be at the heart of future explorations in the social sciences. The mesosocial order and the multilevel dimension of social phenomena show that systems of superimposed interdependencies (one interorganizational, the other interindividual) create dynamics specific to each level. But because levels are partly interlocked, dynamics across levels drive each other. Drawing on Simmel's (1908/2009) ideas about social circles and Breiger's (1974) "dual" approach to the coconstitution of individuals and groups in society, sociologists have begun to look at the dynamics of multilevel structure and their consequences for societies (Lazega \& Snijders, 2016).

Articulation of distinct levels of action for that purpose can be partly accounted for, beyond bipartite structures, with a method called structural linked design, which brings together networks of different levels by using individuals' affiliation ties, be they single or multiple (see Fig. 7.1). Statistical analyses of linked-design data (Wang, Robins, Pattison, \& Lazega, 2013; 2015) show that two levels are not just superimposed but highly intertwined without being necessarily rigidly nested. That relationship implies that changes in ties at one level contribute to changes in ties at the other level even if the capacity to force changes at the other level varies with socioeconomic attributes of the actors.

At each level actors attempt to structure the contexts of their interactions and have to manage the attendant contextually imposed constraints by trying to redesign their opportunity structures. In this approach each complete network is examined separately and then combined with that of the other level by means of information about each individual's membership in the first network (interindividual) and in one of the organizations of the second network (interorganizational). Work undertaken so far within this framework has shown that dual or multiple positioning in superimposed systems of interdependencies makes it possible to formulate and test precise hypotheses about the relation between members' position in the structure and individual achievements, especially when this positional reckoning is based on 


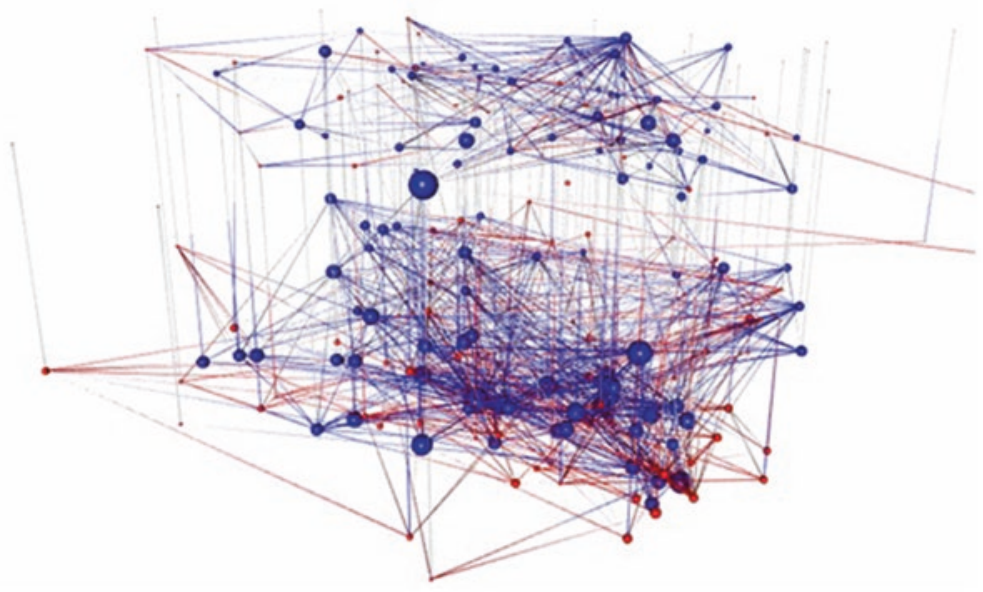

Fig. 7.1 Real life multilevel network based on a linked-design approach to studying an interindividual advice network (bottom), an interorganizational contract network (top), and vertical affiliation ties for the individuals in the organizations (Illustration by J. Brailly)

strategies of actors. Using this multilevel approach and reasoning in terms of the dynamics of these networks will help specify OMRT dynamics.

This form of dual positioning in the structural contextualization of action distinguishes between two levels of agency (one individual, the other organizational) and their coconstitution, but without conflating them. Insofar as each level constitutes a production and exchange system that has its own logic - its own division of labor and system of roles - it is important to examine the various levels separately (as is usually the case in the literature) but also jointly. Studying the levels jointly means identifying, in particular, the actors who profit from comparatively easy access to resources that circulate at each level, and it means measuring their relative achievement. The term strategy refers to the fact that actors manage their interdependencies at different levels by appropriating, accumulating, exchanging, and sharing resources, both with peers and with hierarchical superiors or subordinates. One observes these strategies by looking at the choices made by interindividual and interorganizational exchange partners.

In the multilevel context of this organizational society, individual actors can try to reshape their complex opportunity structure by creating new ties and languages that escape the control of the organizations with which they are affiliated. In the multilevel system actors try to take advantage of spatial and temporal gaps between different levels of agency. By doing so, they reap benefits that may prompt them to move and set up new organizations that are meant to protect access to these benefits and to hoard the new opportunities created by breaking off the constraints that had been imposed on them by their former affiliations and bosses. Under specific circumstances, ongoing interactions between interpersonal and interorganizational 
networks therefore bring about changes, as opposed to mere consolidation, at each level. These changes may be great enough to reconfigure the multilevel system if they drive the creation of new organizational actors (new collectives). Culture plays a substantial part in these dynamics. No collective can be set up without the language needed to formulate the conditions under which "synergy" (Archer, 2013, p. 13) is achieved and without institutionalization of its rules. The major task of culture is thus to produce the language for creating relationships with heterogeneous others and to strengthen the institutional dimension of organizations that emerge from this effort. The multilevel and cultural dimensions of collective action are the two sources of energy that coevolve with OMRT transformations and affect social processes such as collective learning.

Why would individuals willingly incur the costs of adjustments and adaptation? Answers to this question abound. People may be coerced into accepting such behavior if they are the weakest parties in the system. They may want to increase their status. Or it may be culturally and symbolically rewarding to do so. From the perspective of the individual actors, such movements (across places) and associated relational changes are part of the costs or benefits of reshaping opportunity structures, if not opportunity-hoarding, in the organizational and class society. Saying that structure reflects both opportunity and constraint is equivalent to saying that individual actors eventually try to manage the constraints in order to reshape their opportunity structure in this organizational society. The opportunities include, for example, those of landing a job, obtaining funding for a project, arranging credit for an apartment, finding a place in a suitable kindergarten or school for the children, and maintaining a steady flow of business.

Individuals trying to reshape their opportunity structure can be portrayed as strategic, but interdependent, actors who seek contexts in which they can find and exchange these resources at low cost. Once in such contexts they can seek various forms of concentration of these resources - an initial dimension of power - and thereby enable themselves to define the terms of such exchanges, to determine the rules of the game. At the individual level this set of goals is the answer to the question about the source of the energy for rotations and movements across places: It comes from efforts to close the gap between levels of agency. It comes from the competition for status.

This view calls for a contemporary definition of social class that is more complex than existing ones, for relatively invisible dimensions of opportunity structures are growing in significance at the intra- and interorganizational levels. Tilly (1998) offered such an organizational view of mechanisms that generate inequality. They are the organizational structures that allow for exploitation, entrench it, and make it seem natural. From this perspective contemporary social stratification also articulates exploitation (by the elites who hold many of the resources and much of the power in society) and opportunity-hoarding (by intermediary classes) as two complementary means for perpetuating inequality. Opportunity monopolists organize themselves legally and socially in ways far less conspicuous than the distinction 
between the bourgeois and the proletarians, constructing well-organized communities able to dominate the opportunities created by movement. It is not easy to see whether someone has the opportunities that others may not have. These opportunities are comparable to the very efficient implicit or informal rights, often self-granted in an organized group, that are linked to the positions in the inconspicuous relational structure (White, 1970).

Organizations, for example, help align social cleavages to create a system of inequality in which these cleavages reinforce each other, achieving exclusion and exploitation. In the monopolization of opportunities, Tilly (1998) saw the key mechanism that reproduces social inequality, joining the mesosocial level to the macrosocial level. Organizations and stratifications reinforce each other, even though the knowledge of their own opportunity structures for the individual actors is not obvious or the modality and the yield of monopolizing are not mechanical. They depend on the link-up of a long-term process at the macrolevel and the operations of local organizations with their stabilized and specific social disciplines. The starting point proposed by Tilly is a complex socioeconomic process at the heart of the neostructural approach to relations between the meso- and macrosocial levels. Neostructural sociologists can measure and model this monopolization by using social and organizational network analysis as a method that was developed for updating the various forms of conflicts and interdependencies between actors and between categories of actors.

If synchronization is necessary for the organization to benefit from the individual action of its members, especially from individual action that takes place outside the organization, creating asynchronies is sometimes what helps individuals break free. Collective action at two vertically interdependent levels of agency can thus also be a story of one level's emancipation from the influence of the other and of either catching up with that other level or creating a new emergent structure (or, more modestly, a new substructure). The lag between the two vertically interdependent levels of collective agency can be considered the main source of morphogenesis, and the generalization of lags can be seen as the cause of morphogenesis unbound: Structuration at one level drives structuration at the other in mostly conflicting, chaotic, and unequal ways. There is not always time to adjust and adapt; enormous waste and disorganization may characterize the multilevel structuration process. ${ }^{9}$ When agents emancipate and create their own organizations, structure and culture

\footnotetext{
${ }^{9}$ Because this morphogenesis creates dynamics of multilevel networks marked by different levels of agency, a new family of models is needed to account for such dynamics. This family of models could be a multilevel extension of Snijders's (1996) model of network dynamics and could use characteristics of a level 2 network as a set of exogenous factors in the evolution of a level 1 network and vice versa. The coevolution of both level networks is added to the coevolution of behavior and relational choices. In terms of model specification, new independent variables from interorganizational networks operate at the interindividual level and vice versa. A multilevel version of Snijders's model of network dynamics could, for example, introduce dual alters or induced potentials (extended opportunity structures as defined by Lazega et al., 2013) into Snijders's formalism in order to propose concepts such as multilevel closure and to measure the effects that one level of agency has on the other.
} 
can be brought together as status and rules by which opposing parties collaborate nevertheless. Catching up "depends upon the swift succession of positive feedback cycles..., all of which lead to new variety fostering further variety" (Archer, 2013, p. 14).

It also matters who manages to stabilize their powerful position in multilevel, OMRT systems. Analyses in the courthouse case study above show that organizational members who have enough staying capacity, status, and epistemic authority also represent specific forces in the joint regulation of markets: bankers with a law degree. The study shows that advice-seeking does converge toward central and supercentral members and reflects a process of epistemic alignment with members who have gained the authority to know, who provide social approval for specific decisions. Actors and their groups do not learn mechanically. This capacity to learn collectively depends particularly on their stability and reframing capacities in changing networks, that is, on their switching capacities across social boundaries (Breiger, 2010; White, 2008). Members with specific forms of status frame collective action by providing the judgments of appropriateness that are shared in collective learning (Lazega, 1992).

OMRT is thus based on limited transformation of the structure (examined in this chapter through the status system), which could nevertheless either be controlled homeostatically or change more profoundly. This juncture is where such transformation can, in turn, change the social processes that help members manage the problems of collective action.

\section{Endogenizing Systems of Places: OMRT Research Agenda for Sociology and Geography}

Reasoning in terms of OMRT dynamics is important because it helps one understand how stability in the system can be precisely created by the enormous quantity of movement that it organizes, directly or indirectly. New attention to OMRT dynamics is also needed because they assume new forms in contemporary society (Archer, 2013, 2014). Speed matters more than ever in everything, members are exposed to increasingly open competition as they descend through the social hierarchy, and social control has become ever more intrusive. When various sorts of mobility slow down or accelerate, new people are left behind and disenfranchised in many respects, exclusion that reproduces or creates new social inequalities and hierarchies. Actors who know how to instrumentalize organizations do better than others because they can navigate or even reshape the prior system of places. Relational capital of individuals and social capital of organizations have always been leading determinants of inequalities (Breiger, 1990, 2011). Some people's movements and mobility create and recreate the stability and wealth of other people, including the capacity of those others to acquire and capitalize resources (e.g., status) and 
positions (e.g., niches) in advantageous relational infrastructures. In the organizational society individuals are part of organizational systems, and organizations are part of interorganizational systems. The coevolution of the levels is not necessarily peaceful and harmonious. Synchronization entails costs of adaptation to the other level, and the costs of adjustments in dual and asynchronized opportunity structures are dumped onto the weakest parts of the system (Lazega, 2013, 2014, 2015). These costs can be measured only if one understands how OMRT dynamics shape the coevolutionary, recursive nature of the transformations they create-that is, structural emergence.

Much remains to be done to carry out this program. Changes in social mechanisms that help members of collective actors manage the problems of collective action are occurring in contexts defined more and more by OMRT dynamics and structuration derivable from residential, educational, and professional forms of mobility. Collective learning is only one of the processes that help members of society deal with these dilemmas (Glückler \& Hammer, 2012, 2014; Lazega, 2012). The capacity of societies to adapt to changes and environments that they themselves have brought about depends on their OMRT dynamics.

In addition, this chapter's exclusive emphasis on status as a relational infrastructure of vertical differentiation is due only to lack of space. Other such social forms, such as horizontally discrete social niches and systems of niches, can be regarded as linchpins between OMRT and collective action. They represent forms of the social division of labor in all socially organized contexts, with their multilevel and superimposed role systems. Social niches in their system of niches are among the relational infrastructures that precondition social processes such as solidarity and social control. They are part of the definition of the initial system of places across which mobility takes place to begin with. Niches and status alike are forms by which socially rational actors seek to structure the contexts of their interactions and their social and economic exchanges. If the changes in the system of places itself are interpreted as OMRT driven and as the ultimate expression of domination, then places will no longer be regarded as exclusively exogenous entities in the social sciences but rather as coevolutionary detrminants and outcome of social processes.

It is fundamental to understand that the links between interdependent processes also have an effect on the relational infrastructures reconstituted by the observer and endogenized by the actors. These effects lie at the origin of the dynamics of relational structures: New rules can reconfigure a system of niches; exercise of social control can encourage the emergence of new forms of social status and modify principles of status consistency. In turn, the new processes that result from these changes facilitate new modes of coordination. To improve the understanding of what agency means in this interpersonal, interorganizational, and dynamic context, neostructural sociologists must still develop methods that combine the systematic study of longitudinal and multilevel data on identities, trajectories (in the long term), exchange networks, and representations (or controversies). The fact that new rules can reconfigure a system of places is not obvious. Orthodox structuralists have challenged such statements (Pizarro, 1999, 2007). It is on this point that sociolo- 
gists, geographers, and historians need to collaborate when pursuing the joint research agenda of tracking OMRT and their effects on collective action.

Indeed, it may be that the social sciences are able to treat these systems of places, these forms of the division of labor, as endogenous only with the assistance of geographers or other specialists on spatial and organizational movement (Bathelt \& Glückler, 2011; Glückler, 2012, 2013). Geographers become crucial in the description and modeling of OMRT dynamics of all kinds because the social reality that such researchers observe is spatial, organizational, relational, multilevel, and dynamic. Contemporary public statistical datasets are ill suited for this purpose and for the measurement of OMRT dynamics in interaction with social stratification in the organizational society. Geographers and sociologists can design joint research projects on residents switching neighborhoods (e.g., Lévy, 1998), people migrating from countryside to the city and back (Lemercier \& Rosental, 2008), entire populations making an exodus from one continent to the other, and the changes occurring at the meso- and macrolevels because of such movements. Much of what happens in social life at meso and macro levels combined is OMRT-related phenomena characterized by the dynamics of multilevel structures where relational infrastructures necessarily function as gears driving evolution. They can be reconstituted in all areas of social life provided that a longitudinal perspective articulates coevolutionary changes across places (mobility) and in relationships (networks). Neostructural sociologists argue that social change at the mesolevel must be examined process by process at each level of agency (interindividual or interorganizational). To describe and analyze these systems adequately, the challenge is in observing and reconstructing these combined dynamics in interdisciplinary collaboration conceived to make sense of vast amounts of heterogeneous data gathered on various scales. That work will provide the framework for building a general theoretical approach to such OMRT phenomena with up- and down-stream effects.

Mapping and modeling OMRT is how geographers and sociologists can account for the link between the meso- and macrolevels, indeed for the way in which mesolevel actors build the macrolevel. Therefore, their function in documenting and explaining social change is to explore these OMRT dynamics at multiple levels simultaneously. These modalities are the ways in which actors manage the multilevel dimension of their society, moving (or not) from one level to the other and organizing these adjustments and their costs. As shown in analyses of regulation and governance, such exploration can yield a theory of action to guide dynamic, multilevel modeling and, eventually, to afford a fresh look at politics. In this respect much remains to accomplish.

Acknowledgment I thank David Antal, Julien Brailly, Johannes Glückler, and Andreas Kalström for very helpful suggestions. Support for writing this chapter was provided by Sorbonne Paris-Cité as part of the program Dynamique des réseaux multiniveaux (DYREM). 


\section{References}

Archer, M. S. (1988). Culture and agency. Cambridge, UK: Cambridge University Press.

Archer, M. S. (Ed.). (2013). Social morphogenesis. Studies in Social Morphogenesis: Vol. 1. Dordrecht: Springer.

Archer, M. S. (Ed.). (2014). Late modernity: Trajectories towards morphogenic society. Studies in Social Morphogenesis: Vol. 2. Dordrecht: Springer.

Bathelt, H., \& Glückler, J. (2011). The relational economy: Geographies of knowing and learning. Oxford: University Press.

Blau, P. M. (1955). The dynamics of bureaucracy. Chicago: University of Chicago Press.

Blau, P. M. (1964). Exchange and power in social life. New York: John Wiley \& Sons.

Brailly, J., Favre, G., Chatellet, J., \& Lazega, E. (2015). Embeddedness as a multilevel problem: A case study in economic sociology, Social Networks. Advance online publication. http://dx.doi. org/10.1016/j.socnet.2015.03.005

Breiger, R. L. (1974). The duality of persons and groups. Social Forces, 53, 181-190. doi:10.2307/2576011

Breiger, R. L. (1990). Social mobility and social structure. Cambridge, UK: University Press.

Breiger, R. L. (2010). Dualities of culture and structure: Seeing through cultural holes. In J. Fuhse \& S. Mützel (Eds.), Relationale Soziologie. Zur kulturellen Wende der Netzwerkforschung (pp. 37-47). Dordrecht: Springer.

Breiger, R. L. (2011). Some challenges in multilevel social network research. Keynote address at the Conference on Research on the Organizational Society: Advances in Multilevel and Dynamic Network Analysis, Observatoire des Réseaux Intra- et Inter-Orgaisationnels (ORIO), Dauphine, France.

Frank, R. H. (1985). Choosing the right pond: Human behavior and the quest for status. Oxford: University Press.

Glückler, J. (2012). Organisierte Unternehmensnetzwerke: Eine Einführung [Introduction to organized corporate networks]. In J. Glückler, W. Dehning, M. Janneck, \& T. Armbrüster (Eds.), Unternehmensnetzwerke. Architekturen, Strukturen und Strategien (pp. 1-18). Heidelberg: Springer Gabler.

Glückler, J. (2013). The problem of mobilizing expertise at a distance. In P. Meusburger, J. Glückler, \& M. el Meskioui (Eds.), Knowledge and the economy (pp. 95-109). Knowledge and Space: Vol. 5. Dordrecht: Springer.

Glückler, J., \& Hammer, I. (2012). Multilaterale Kooperation und Netzwerkgüter [Multilateral cooperation and network goods]. In J. Glückler, W. Dehning, M. Janneck, \& T. Armbrüster (Eds.), Unternehmensnetzwerke. Architekturen, Strukturen und Strategien (pp. 139-162). Heidelberg: Springer Gabler.

Glückler, J., \& Hammer, I. (2014). Organized networks and the creation of network goods. Unpublished manuscript, Department of Geography, University of Heidelberg, Germany.

Hughes, E. C. (1945). Dilemmas and contradictions of status. American Journal of Sociology, 50, 353-359. Retrieved from http://www.jstor.org/stable/2771188

Kane, A. A., Argote, L., \& Levine, J. M. (2005). Knowledge transfer between groups via personnel rotation: Effects of social identity and knowledge quality. Organizational Behavior and Human Decision Processes, 96, 56-71. doi:10.1016/j.obhdp.2004.09.002

Krackhardt, D. (1990). Assessing the political landscape: Structure, cognition, and power in organizations. Administrative Science Quarterly, 35, 342-369. doi:10.2307/2393394

Larsson, R., Bengtsson, L., Henriksson, K., \& Sparks, J. (1998). The interorganizational learning dilemma: Collective knowledge development in strategic alliances. Organization Science, 9, 285-305. http://dx.doi.org/10.1287/orsc.9.3.285

Lazega, E. (1992). Micropolitics of knowledge: Communication and indirect control in workgroups. New York: Aldine-de Gruyter. 
Lazega, E. (2001). The collegial phenomenon: The social mechanisms of cooperation among peers in a corporate law partnership. Oxford: University Press.

Lazega, E. (2003). Rationalité, discipline sociale et structure [Rationality, social discipline, and structure]. Revue Française de Sociologie, 44, 305-329. doi:10.3917/rfs.442.0305

Lazega, E. (2009). Cooperation among competitors: Its social networks through network analyses. SocioLogica [Italian Journal of Sociology Online, 1]. doi:10.2383/29560. With comments by L. Burroni, S. Mützel, \& H. C. White: http://www.sociologica.mulino.it/journal/issue/index/ Issue/Journal:ISSUE:7

Lazega, E. (2011). Four and half centuries of new (new) law and economics: Legal pragmatism, discreet joint regulation and institutional capture at the Commercial Court of Paris. In U. de Vries \& L. Francot-Timmermans (Eds.), Law's environment: Critical legal perspectives (pp. 179-204). The Hague: Eleven International Publishing.

Lazega, E. (2012). Sociologie néo-structurale [Neostructural sociology]. In R. Keucheyan \& G. Bronner (Eds.), Introduction à la théorie sociale contemporaine (pp. 113-130). Paris: Presses Universitaires de France.

Lazega, E. (2013). Network analysis and morphogenesis: A neo-structural exploration and illustration. In M. S. Archer (Ed.), Social morphogenesis (pp. 167-186). Studies in Social Morphogenesis: Vol. 1. Dordrecht: Springer.

Lazega, E. (2014). Morphogenesis unbound from the dynamics of multilevel networks: A neostructural perspective. In M. S. Archer (Ed.), Late modernity: Trajectories towards morphogenic society (pp. 173-191). Studies in Social Morphogenesis: Vol. 2. Dordrecht: Springer.

Lazega, E. (2015). Body captors and network profiles: A neo-structural note on digitalized social control and morphogenesis. In M. S. Archer (Ed.), Generative mechanisms transforming the social order (pp. 113-133). Studies in Social Morphogenesis: Vol. 3. Dordrecht: Springer.

Lazega, E., \& Favereau, O. (2002). Introduction. In O. Favereau \& E. Lazega (Eds.), Conventions and structures in economic organization: Markets, networks, and hierarchies (pp. 1-28). Cheltenham: Edward Elgar.

Lazega, E., Jourda, M.-T., \& Mounier, L. (2013). Network lift from dual alters: Extended opportunity structures from a multilevel and structural perspective. European Sociological Review, 29, 1226-1238. doi:10.1093/esr/jct002

Lazega, E., \& Snijders, T. A. B. (Eds.). (2016). Multilevel network analysis for the social sciences: Theory, methods and applications (Methodos series). Dordrecht: Springer.

Lazega, E., Jourda, M.-T., Mounier, L., \& Stofer, R. (2008). Catching up with big fish in the big pond? Multi-level network analysis through linked design. Social Networks, 30, 159-176. http://dx.doi.org/10.1016/j.socnet.2008.02.001

Lazega, E., Lemercier, C., \& Mounier, L. (2006). A spinning top model of formal structure and informal behavior: Dynamics of advice networks among judges in a commercial court. European Management Review, 3, 113-122. doi:10.1057/palgrave.emr.1500058

Lazega, E., \& Mounier, L. (2002). Interdependent entrepreneurs and the social discipline of their cooperation: The research program of structural economic sociology for a society of organizations. In O. Favereau \& E. Lazega (Eds.), Conventions and structures in economic organization: Markets, networks, and Hierarchies (pp. 147-199). Cheltenham, Edward Elgar.

Lazega, E., \& Mounier, L. (2009). Polynormativité et contrôle social du monde des affaires: le exemple de l'interventionnisme et de la punitivité des juges du Tribunal de Commerce de Paris [Polynormativity and social control in the business world: Judges' interventionism and punitivity at the Paris Commercial Court]. Droit et Société, 71, 103-132. Retrieved from http://basepub.dauphine.fr/xmlui/bitstream/handle/123456789/4594/Polynormativite.PDF?sequence $=2$

Lazega, E., \& Mounier, L. (2012). Networks of institutional capture. In B. Vedres \& M. Scotti (Eds.), Networks in social policy problems (pp. 124-137). Cambridge, UK: University Press. 
Lazega, E., Mounier, L., Snijders, T. A. B., \& Tubaro, P. (2012). Norms, status and the dynamics of advice networks, Social Networks, 34, 323-332. doi:10.1016/j.socnet.2009.12.001

Lazega, E., \& Pattison, P. E. (1999). Multiplexity, generalized exchange and cooperation in organizations: A case study. Social Networks, 21, 67-90. doi:10.1016/S0378-8733(99)00002-7

Lazega, E., Sapulete, S., \& Mounier, L. (2011). Structural stability regardless of membership turnover? The added value of blockmodelling in the analysis of network evolution. Quality \& Quantity, 45, 129-144. doi:10.1007/s11135-009-9295-y

Lazega, E., \& van Duijn, M. (1997). Position in formal structure, personal characteristics and choices of advisors in a law firm: A logistic regression model for dyadic network data. Social Networks, 19, 375-397. http://dx.doi.org/10.1016/S0378-8733(97)00006-3

Lemercier, C., \& Rosental, P.-A. (2008, September). Les migrations dans le Nord de la France au XIXe siècle. Nouvelles approches, nouvelles techniques en analyse des réseaux sociaux [Migrations in northern France in the nineteenth century: New approaches, new techniques in analysis of social networks]. Lille, France. Retrieved from https://halshs.archives-ouvertes.fr/ halshs-00319448

Lenski, G. E. (1954). Status crystallization: A non-vertical dimension of social status. American Sociological Review, 19, 405-413. Retrieved from http://www.jstor.org/stable/2087459

Lévy, J.-P. (1998). Dynamiques du peuplement résidentiel [Dynamics of residential settlement]. Sociétés Contemporaines, 29, 43-72.

March, J. G., \& Simon, H. A. (1958). Organizations. New York: John Wiley \& Sons.

Merton, R. K. (1957). Social theory and social structure (2nd ed.). New York: Free Press.

Merton, R. K. (1968). The Matthew effect in science. Science, 159, 56-63. doi:10.1126/ science. 159.3810 .56

Ortega, J. (2001). Job rotation as a learning mechanism. Management Science, 47, 1361-1370. doi: $10.12 .87 /$ mnsc.47.10.1361.10257

Perrow, C. (1991). A society of organizations. Theory and Society, 20, 725-762. doi:10.1007/ BF00678095

Pizarro, N. (1999). Appartenances, places et réseaux de places. La reproduction des processus sociaux et la génération d'un espace homogène pour la définition des structures sociales [Appearance, places, and network places: The reproduction of social processes and the generation of a homogeneous space for the definition of social structures]. Sociologie et Societies, 31, 143-161. doi:10.7202/001568ar

Pizarro, N. (2007). Structural identity and equivalence of individuals in social networks, beyond duality. International Sociology, 22, 767-792. doi:10.1177/0268580907082260

Selznick, P. (1949). TVA and the grassroots: A study in the sociology of formal organization. Berkeley: University of California Press.

Simmel, G. (2009). Inquiries into the construction of social forms (A. J. Blasi, A. K. Jacobs, \& M. Kanjirathinkal, Eds. \& Trans., with an introduction by H. J. Helle). 2 Vols. Leiden: Brill. (Original work published 1908)

Snijders, T. A. B. (1996). Stochastic actor-oriented models for network change. Journal of Mathematical Sociology, 21, 149-172. doi:10.1080/0022250X.1996.9990178

Snijders, T. A. B. (2005). Models for longitudinal network data. In P. J. Carrington, J. Scott, \& S. Wasserman (Eds.), Models and methods in social network analysis (pp. 215-247). Cambridge, UK: University Press.

Tilly, C. (1998). Durable inequality. Berkeley: University of California Press.

Wang, P., Robins, G., Pattison, P., \& Lazega, E. (2013). Exponential random graph models for multilevel networks. Social Networks, 35, 96-115. doi:10.1016/j.socnet.2013.01.004

Wang, P., Robins, G., Pattison, P., \& Lazega, E. (2015). Social selection models for multilevel networks. Social Networks. Advance online publication. http://dx.doi.org/10.1016/j. socnet.2014.12.00

Weber, M. (1924). Gesammelte Aufsätze zur Soziologie und Sozialpolitik [Collected essays on sociology and social policy]. Tübingen: J. C. B. Mohr. 
White, H. C. (1970). Chains of opportunity: System models of mobility in organizations. Cambridge, MA: Harvard University Press.

White, H. C. (2008). Identity and control: How social formations emerge (2nd ed.). Princeton: University Press.

White, H. C., Boorman, S. A., \& Breiger, R. L. (1976). Social structure from multiple networks, In: Blockmodels of roles and positions. American Journal of Sociology, 81, 730-780.

Open Access This chapter is distributed under the terms of the Creative Commons Attribution 4.0 International License (http://creativecommons.org/licenses/by/4.0/), which permits use, duplication, adaptation, distribution and reproduction in any medium or format, as long as you give appropriate credit to the original author(s) and the source, provide a link to the Creative Commons license and indicate if changes were made.

The images or other third party material in this chapter are included in the work's Creative Commons license, unless indicated otherwise in the credit line; if such material is not included in the work's Creative Commons license and the respective action is not permitted by statutory regulation, users will need to obtain permission from the license holder to duplicate, adapt or reproduce the material. 